Document downloaded from:

http://hdl.handle.net/10251/104020

This paper must be cited as:

Broatch, A.; Olmeda, P.; García Martínez, A.; Salvador-lborra, J.; Warey, A. (2017). Impact of swirl on in-cylinder heat transfer in a light-duty diesel engine. Energy. 119:1010-1023. doi:10.1016/j.energy.2016.11.040

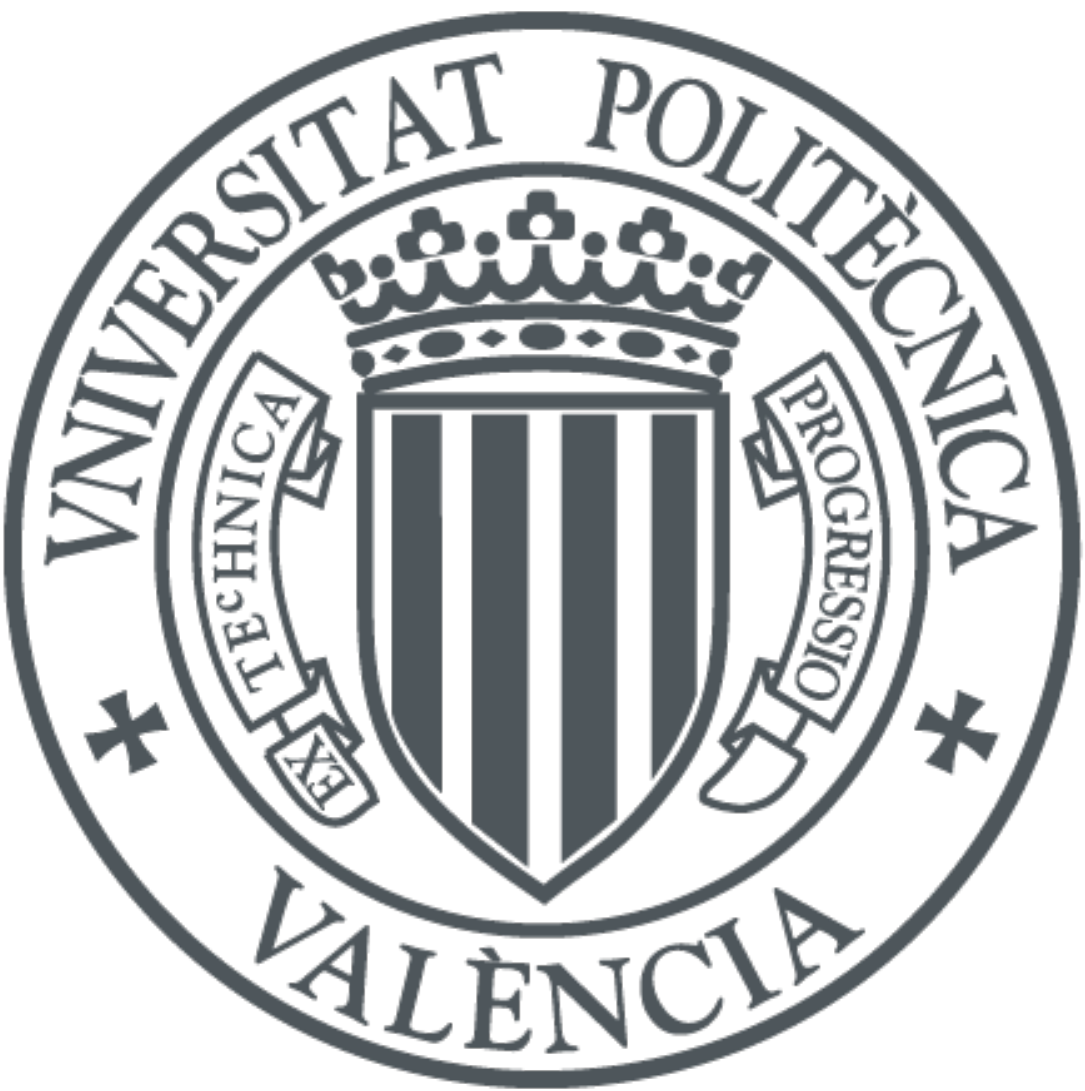

The final publication is available at

http://dx.doi.org/10.1016/j.energy.2016.11.040

Copyright Elsevier

Additional Information 


\title{
Impact of swirl on in-cylinder heat transfer in a light-duty diesel engine
}

\author{
Alberto Broatch ${ }^{a}$, Pablo Olmeda ${ }^{* a}$, Antonio García ${ }^{a}$, Josep Salvador-Iborra ${ }^{a}$, Alok Warey ${ }^{b}$ \\ ${ }^{a}$ CMT-Motores Térmicos, Universitat Politècnica de València, Camí de Vera s/n, 46022 Valencia, Spain \\ ${ }^{b}$ Propulsion Systems Research Lab, General Motors Global Research and Development, United States
}

\begin{abstract}
One of the key strategies to reduce $\mathrm{CO}_{2}$ emissions is to improve the efficiency of engines in order to diminish fuel consumption. A way to increase engine efficiency is to reduce the heat losses. Internal heat transfer in engines depends on combustion chamber conditions. Swirl is an important parameter for combustion that also changes in-cylinder variables relevant to heat transfer. In this work, influence of swirl on combustion chamber heat fluxes was investigated employing wall temperature data and a 0-D thermal model. Local wall temperatures were measured at various locations of the cylinder liner and the cylinder head using thermocouples. A sweep of swirl ratios was carried out at different engine operating conditions. It was observed that the effect of swirl effect was highly dependent on location and was more important near the center of the firedeck.

Results from the $0-\mathrm{D}$ thermal model were evaluated by comparing measured and predicted wall temperatures. Using a convenient arrangement of thermocouples and the 0-D thermal model, it was possible to calculate heat flux from combustion chamber to cylinder walls. By analyzing heat flux through the firedeck, an increase in heat losses between 4 and $12 \%$ was observed for each unit that swirl number was increased. Results from the 0-D thermal model indicate that similar effects occur for other surfaces in the combustion chamber.
\end{abstract}

Keywords: swirl, wall temperature, heat transfer, heat flux, heat losses

\section{Introduction}

Reduction of greenhouse gas emissions has become a serious concern for the automotive industry [1]. $\mathrm{CO}_{2}$ emissions, as the main contributor to greenhouse effect, can be lessened by diminishing fuel consumption

Abbreviations: $\mathrm{CO}_{2}$, carbon dioxide; BMEP, break mean effective pressure; cad, crank angle degree; $D$, cylinder bore; CA50, crank angle where $50 \%$ of the total heat has been released; DI, direct injection; EGR, exhaust gas recirculation; $h$, heat transfer coefficient; IVC, intake valve closing; $L$, length $p$, pressure; $Q$, heat flux; $\Delta Q$, heat flux increment; RoHR, rate of heat release; RTD, resistance temperature detector; SN, swirl number or swirl ratio; $T$, temperature; $\Delta T$, temperature increment; $\nabla T$, temperature gradient; TDC, top dead center; ATDC, after top dead center; $V$, volume; $V_{d}$, displaced volume; $\beta$, exponent of Reynolds number.

* Corresponding author. Tel.: +34 963877650; fax: +34 963877659.

E-mail address: pabolgon@mot.upv.es (P. Olmeda). 
or increasing engine thermal efficiency.

Heat losses have a strong influence on engine efficiency [2]. Energy lost through the cylinder walls is not available to produce mechanical work, which results in reduction of indicated efficiency. In the intake ports, heat transfer from walls to the intake air increases charge temperature, diminishing volumetric efficiency. In the exhaust ports, heat losses from exhaust gas reduce the amount of energy that can be recovered in the turbocharger. In addition, heat transfer is linked to combustion anomalies such as flame quenching and lubrication problems due to oil degradation at high temperatures. Heat transfer is also relevant because it affects gas and surface temperatures, which have an important influence on the formation of pollutants like $\mathrm{NO}_{x}$ (oxides of nitrogen) [3], $\mathrm{CO}$ (carbon monoxide) [4] or unburned hydrocarbons [5]. Thus, the general aim of this paper is to increase knowledge related to in-cylinder heat transfer with the purpose of contributing to efficiency improvement.

Wall temperatures are a good indicator of heat transfer. Heat transfer by convection is proportional to the difference between fluid and wall temperatures. Conductive heat fluxes also depend on wall temperature distribution. Finally, radiation heat transfer is proportional to the difference of temperatures to the fourth power [6]. Another point of view is that if boundary conditions - such as coolant, oil, intake air and ambient temperatures - are maintained constant, then variations in wall temperatures will depend only on combustion chamber conditions. Hence, the influence of engine operating parameters on heat losses can be studied by understanding the effects of those parameters on wall temperatures and heat fluxes.

This study uses a set-up and thermocouple instrumentation similar to those described by Alkidas [7] or Finlay and Gallacher [8]. In the present work, temperature analysis is focused on mean temperatures within chamber walls measured under steady-state operation. For this purpose, slow-response thermocouples are a reliable, flexible and proven solution that provides enough accuracy. Heat flux is not measured by means of heat flux probes because they disturb the temperature field in the metal wall [9]. Instead, thermocouples in cylinder head have been arranged in a configuration that allows calculating the axial component of heat flux through the material. An application of this technique can be found in reference [10].

Influence of swirl on engine performance is a topic that has been documented often in literature. Swirl movement is generated in the intake ports. It enhances fuel and air mixing and can provide benefits such as a higher soot oxidation [11] and a shorter combustion duration that permits more flexible injection timing and can improve cycle efficiency [12]. However, very high levels of swirl can hinder combustion because a high angular velocity raises angular momentum and can prevent proper mixing. For example, there may be interference among jets or fuel may move away from oxygen-rich regions, as explained in [13] or [14]. In addition, a higher swirl velocity implies a higher convective heat transfer coefficient because total gas speed increases [15]. Forced convection in a turbulent flow takes place inside the cylinder. As a result, gas velocity has an important influence on the value of the heat transfer coefficient. In fact, most correlations for calculating that coefficient include a representative speed [16]. Convective heat flux is proportional to heat transfer coefficient.

To investigate the effect of swirl on heat transfer, different tools and approaches have been used. Hohenberg [17] instrumented the firedeck with thermocouples and measured surface temperatures in motoring conditions. Two swirl levels were tested and temperature variations were correlated to velocity differences. Arcoumanis et al. [18] simulated swirl flow to study heat transfer during spray/wall interaction. Later, he measured instantaneous temperatures on the surface of an engine piston with two levels of swirl. Wiedenhoefer and Reitz [19] presented results obtained from CFD simulations regarding the effect of swirl on radiation and total heat losses. More recently, De La Morena [14] assessed the influence of swirl ratio on several parameters by experimental and computational means. All experiments demonstrated that the effect of swirl on heat transfer is significant.

The main objective of this work was to assess the impact of swirl on in-cylinder heat transfer by analyzing wall temperatures and heat fluxes. Quantitative effects of swirl on wall temperatures were analyzed locally. Influence of swirl on various engine operating conditions was studied. Results obtained from a 0-D thermal model were compared to experimental measurements in order to evaluate its ability to predict temperatures and trends. Lastly, heat fluxes were analyzed. For the cylinder head, experimental heat fluxes were 
estimated from axial temperature gradients. They were compared with heat fluxes calculated by the thermal model. The 0-D model was also used to calculate heat losses for other combustion chamber surfaces.

\section{Modeling tools}

\subsection{0-D Thermodynamic model: CALMEC}

CALMEC is a tool for combustion diagnosis. Its main input is the in-cylinder pressure signal [20]. Data from 25 engine cycles is collected, filtered and averaged to obtain a representative pressure trace. Then, the first law of thermodynamics is applied between IVC (intake valve closing) and EVO (exhaust valve opening) to calculate the Rate of Heat Release as the main result [21].

$$
R o H R=m C_{V} \frac{d T}{d \alpha}+\frac{d Q}{d \alpha}+p \frac{d V}{d \alpha}-\left(h_{f, i n j}-u_{f, g}\right) \frac{d m_{f, e v}}{d \alpha}+R T \frac{d m_{b b}}{d \alpha}
$$

where $\alpha$ is the crank angle degree, $m, d T, d V$ and $d Q$ are the instantaneous mass in the chamber, gas temperature variation, volume variation and instantaneous heat transfer to the chamber walls respectively, $C_{V}$ is the specific heat which depends on the instantaneous temperature and composition, $d m_{f, e v}$ is the variation of injected mass, $h_{f, i n j}$ and $u_{f, g}$ are the injected fuel enthalpy and internal energy of the evaporated fuel, $R$ is the gas constant and $d m_{b b}$ is the variation of blow-by leakage.

Main assumptions of CALMEC are: gas pressure and temperature are assumed to be spatially uniform inside the combustion chamber; ideal gas law is used to calculate instantaneous gas temperature from pressure signal; three species are considered: air, fuel and stoichiometric combustion products; trapped mass is calculated by means of a filling and emptying model [22]; specific heat of the gas depends on both temperature and composition [23]; blow-by model is based on the evolution of gas in an isentropic nozzle [24]; chamber volume deformation due to pressure and inertia is calculated with a simple deformation model [25]; and a lumped conductance heat transfer model allows for calculation of wall temperatures and heat fluxes.

Instantaneous heat transfer coefficient to the chamber walls is calculated with a modified Woschni correlation [26]:

$$
h=C_{0} D^{\beta-1} p^{\beta} T^{0.75-1.62 \beta}\left[C_{W 1} c_{m}+C_{W 2} c_{u}+C_{2} \frac{V_{d} T_{I V C}}{p_{I V C} V_{I V C}}\left(p-p_{0}\right)\right]^{\beta}
$$

where $c_{m}$ is the mean piston speed, $c_{u}$ is the instantaneous tangential velocity of the gas integrated over the chamber volume, $p_{0}$ is the pressure under motoring conditions assuming a polytropic evolution, $C_{0}, \beta$ and $C_{2}$ are constants whose values are respectively $0.012,0.8$ and $1.05 \times 10^{-3} \cdot C_{W 1}$ and $C_{W 2}$ were adjusted for the present engine: $C_{W 1}$ has values of 0.85 during the closed cycle and 3.09 during the open cycle and $C_{W 2}$ is equal to 0.29 during the closed cycle and 0.21 during the open cycle. Methodology to adjust constants is explained in reference [27]. A single heat transfer coefficient is used for all chamber surfaces. Then, mean gas temperature over an entire engine cycle is calculated from instantaneous temperature and heat transfer coefficient as:

$$
\bar{T}_{\text {gas }}=\frac{\sum h T_{\text {gas }}}{\sum h}
$$

The relevance of Calmec for this study lies in the fact that it supplies the boundary conditions for the thermal model.

\subsubsection{0-D Thermal model}

The 0-D thermal model used in this study is a thermal resistor network [28] integrated in the combustion diagnosis tool CALMEC. At every node of the network, a heat balance is established that takes into account the heat transfer processes with the surrounding nodes (conduction, convection and radiation) [29]. For 
every node a temperature is calculated. Nodes represent volumes of the engine material or specific elements of the engine (such as valves or pipes) [30]. The model has demonstrated to be sensitive to operational parameters like engine speed, load, coolant and oil temperatures, start of injection and intake pressure [31]. Main advantages of lumped conductance networks are: their computational demand is relatively low when compared to finite element methods [32], they can provide an accurate account of boundary conditions [33] and they allow scalability in complexity.

Inputs required by the present model include geometrical characteristics of the engine and mean temperatures of the following fluids: gas in the chamber, intake gas, exhaust gas, coolant and oil. Those inputs are given by CALMEC. Gas chamber temperature is obtained by thermodynamic calculations, as explained in section 2.1. The other fluid temperatures are measured experimentally. Node configuration has been rearranged such that the geometrical center of the node is superimposed on the thermocouple measurement location. In addition, node shapes have been modified to represent the real geometry obtained from engine drawings. Nodes configuration is displayed in Figure 1. The model will be used to calculate temperatures and heat fluxes.

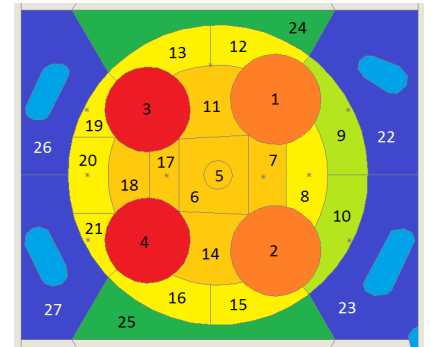

(a) Nodes in firedeck

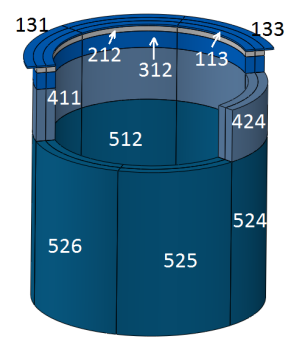

(b) Nodes in liner

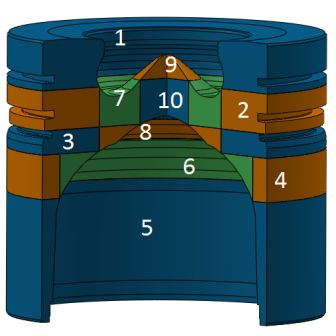

(c) Nodes in piston

Figure 1: Node configuration

\section{Experimental test facility}

The experimental tests were carried out in a production General Motors 1.9L diesel engine. The 4-cylinder engine used a Common-Rail fuel injection system, variable geometry turbocharger (VGT) and a high pressure exhaust gas recirculation system. The engine had four valves per cylinder, centrally located injectors, and a re-entrant type piston bowl. Engine speed was controlled by an electric dynamometer directly coupled to the engine. The swirl number could be varied from 1.38 up to 2.95 with a swirl flap. These were obtained on a dedicated experimental facility. On the flow test bench swirl measurements are executed by the determination of angular moment of momentum. The method measures the angular moment of momentum directly and accurately by transferring the angular moment of momentum on the honeycomb, the resulting torque of which round the vertical axis is measured. The advantage is obvious: no assumptions and direct measurement of the values of interest. The swirl meter is designed to detect the component of the angular moment of momentum vector of the flow around the cylinder axis, which has been induced by the inlet system. The straightening honeycomb has the shape of an even plate, the holes of which are directed exactly parallel to the cylinder axis, which is the measurement axis of the angular moment of momentum. For sealing and damping purposes, the housing of the stratifying honeycomb is immersing into a circular pocket, filled with oil. The system is very robust, absolutely frictionless and wear-free and therefore highly reliable. All relevant engine data as well as details of the injection system are given in Table 1. This engine compliant with EURO IV emissions regulations. Installation also included complete 
instrumentation to measure fluid temperatures and mass flows, listed in Table 2. A combination of K-type thermocouples and resistance temperature detectors (PT100) was used to measure fluid temperatures. Incylinder pressure was measured for each cylinder with Kistler $6125 \mathrm{C} 10$ piezoelectric transducers mounted in the glow-plug bore and Kistler 4603B10 charge amplifiers. A crank angle increment of 0.5 degrees was used for the in-cylinder pressure acquisition, which was performed using a DRIVVEN engine controller [34]. 25 consecutive cycles were measured for the in-cylinder pressure data. DRIVVEN also allowed setting parameters related to injection, charging, swirl and EGR. Mean variables were acquired at a low sample frequency of $100 \mathrm{~Hz}$ using SAMARUC, a test system developed in-house at CMT, that collects the signals of different sensors [35]. In order to ensure that coolant, oil, fuel and air temperature were maintained constant, four conditioning circuits controlled by PID were used.

Table 1: Engine specifications.

\begin{tabular}{ll}
\hline Engine type & DI, 4-cylinder, 4 stroke \\
Displaced volume & $1.9 \mathrm{l}$ \\
Bore & $82 \mathrm{~mm}$ \\
Stroke & $90.4 \mathrm{~mm}$ \\
Maximum power & $110 \mathrm{~kW} @ 4000 \mathrm{rpm}$ \\
Maximum torque & $320 / 2000-2750\left(\mathrm{Nm} / \mathrm{min}^{-1}\right)$ \\
Injection system & Bosch common rail (solenoid) \\
\hline
\end{tabular}

Table 2: Test cell instrumentation.

\begin{tabular}{llc}
\hline Variable & Sensor & Range \\
\hline Temperature of gases & K-type thermocouples & -200 to $1250{ }^{\circ} \mathrm{C}$ \\
Temperature of liquids & RTD (PT100) & -30 to $350{ }^{\circ} \mathrm{C}$ \\
In-cylinder pressure & Kistler 6125C10 & $0-300 \mathrm{bar}$ \\
Torque & Dynamometer & $0-500 \mathrm{~N} \mathrm{~m}$ \\
Air mass flow & AVL Flowsonix air & $0-1400 \mathrm{~kg} / \mathrm{h}$ \\
Fuel mass flow & AVL 733s.18 & $0-41.67 \mathrm{~g} / \mathrm{s}$ \\
\hline
\end{tabular}

\subsection{Instrumentation for wall temperature measurement}

The metallic parts around the combustion chamber of the engine are instrumented with 88 K-type thermocouples. In the cylinder head there were 54 thermocouples distributed on two sections perpendicular to the cylinder axis and located $4 \mathrm{~mm}$ and $7 \mathrm{~mm}$ above the firedeck. In the cylinder liner there were 34 thermocouples located $1.3 \mathrm{~mm}$ from the liner surface and in different positions along the piston stroke. Thermocouples were inserted through holes drilled directly in the engine structure. The piston was not instrumented since data transmission from sensors to a recorder is problematic due to piston movement [9].

Locations of thermocouples can be seen in Figure 2. In graph (a), distribution of thermocouples in the firedeck is shown. All thermocouples were on the same plane. Both planes of each cylinder have the same distribution of thermocouples. Other cylinders have less thermocouples but locations are the same. Direction of fuel sprays and location of piston bowl are also indicated in the figure with dashed lines. Regarding the cylinder liner, thermocouples were arranged along a vertical line, as seen in Figure 2 (b). In each cylinder there were four vertical lines of thermocouples separated $90^{\circ}$ from each other. Not all 
lines had four thermocouples. There were more thermocouples close to cylinder top than near the bottom. Top area was considered more interesting because, due to piston movement, it had a longer exposure time to chamber gas. Signals from the thermocouples were received by two data-loggers and then sent to be recorded on a computer.

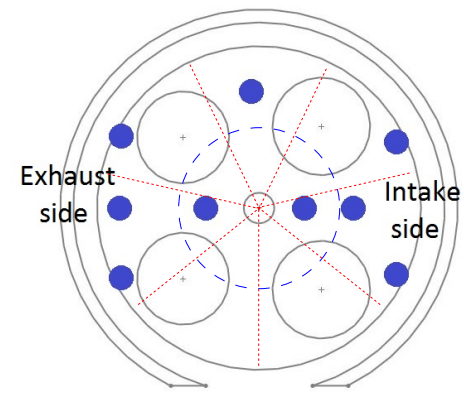

(a) Cylinder head

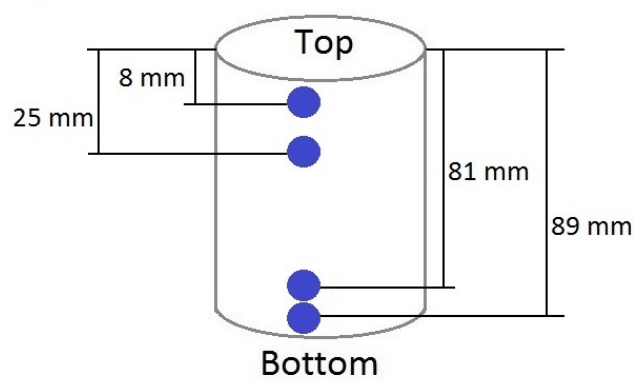

(b) Cylinder liner

Figure 2: Thermocouple distribution

\section{Methodology}

A set of conditions were fulfilled in all tests. Some were limiting values or fixed settings, as those included in Table 3. Peak pressure restraints are defined by the engine manufacturer with the aim of guaranteeing mechanical integrity. Common injection settings facilitated that injected fuel mass could be the same for the entire swirl sweep. Other variables such as trapped mass and temperature at intake valve closure, fuel consumption, and fluid temperatures (coolant, oil, fuel) were maintained constant to allow for a back-to-back comparison and maintain conditions close to those in a production-type engine during normal operation.

Four operating points were tested. For every operating point, the initial test was carried out under conditions of maximum swirl. First, engine speed was set by operating the dynamometer. Swirl valve (shown in Figure 3) opening was adjusted to obtain maximum swirl ratio $(\mathrm{SN}=2.95)$. Main injection timing was set in order to keep CA50 constant. The variable geometry turbine was positioned in the configuration that maximized the intake pressure. Finally, main injection duration was fixed in order to reach the nominal torque (and BMEP) for this operating point. Intake gas mass flow and fuel consumption thus obtained, were maintained during the swirl sweep for each operating point, while torque was allowed to change in response to the variations of the other parameters.

For every operating point and swirl ratio, three repetitions were measured. In each repetition, thermocouple measurements were scanned every four seconds for one minute. Scans were then averaged for each thermocouple and repetition.

\subsection{Operating conditions}

A total of four engine operating points were tested. Selected points were intended to be representative of ordinary operating conditions. Two intermediate values of engine speed (1500 and $2000 \mathrm{rpm}$ ) were chosen. Load values ranged from a low load BMEP of 2 bar (10\% load at $2000 \mathrm{rpm})$ to a high load of 14 bar $(80 \%$ load at $1500 \mathrm{rpm})$. As shown in Table 4, four values of swirl ratio were swept. Altogether, 16 different operating conditions were investigated. To refer to engine operating points, the format [Engine speed in rpm] @ [BMEP in bar] has been used, e.g. 2000@2 is the operating point with engine speed $2000 \mathrm{rpm}$ and 
Table 3: Fixed settings and limiting values.

\begin{tabular}{llccccc}
\hline \multirow{2}{*}{ Operating point } & Speed & rpm & 2000 & 1500 & 1500 & 2000 \\
& BMEP & bar & 2 & 5 & 8 & 14 \\
\hline \multirow{3}{*}{ Limit values } & Peak Firing Pressure & bar & 160 & 160 & 130 & 130 \\
& Pressure Rise Rate & bar/deg & 10 & 10 & 10 & 10 \\
\hline \multirow{2}{*}{ Fixed settings } & CA50 & deg ATDC & 13 & 13 & 13 & 13 \\
& Rail Pressure & bar & 450 & 650 & 750 & 1050 \\
\hline \multirow{5}{*}{ Fixed injection } & Dwell: $1^{\text {st }}$ to $2^{\text {nd }}$ pilot & $\mu \mathrm{s}$ & 800 & 800 & 800 & 800 \\
settings & Dwell: $2^{\text {nd }}$ pilot to main & $\mu$ s & 800 & 800 & 800 & 800 \\
& Fuel mass: $1^{\text {st }}$ pilot & $\mathrm{mg} / \mathrm{cycle}$ & 1.5 & 1.5 & 1.5 & 1.5 \\
& Fuel mass: $2^{\text {nd }}$ pilot & $\mathrm{mg} / \mathrm{cycle}$ & 1.5 & 1.5 & 1.5 & 1.5 \\
\hline \multirow{5}{*}{ Constant temperatures } & ${ }^{\circ} \mathrm{C}$ & 45 & 45 & 45 & 45 \\
& Intake Temperature & ${ }^{\circ} \mathrm{C}$ & 87 & 87 & 87 & 87 \\
& Coolant Outlet Temperature & ${ }^{\circ} \mathrm{C}$ & 95 & 95 & 95 & 95 \\
& Oil Outlet Temperature & ${ }^{\circ} \mathrm{C}$ & 38 & 30 & 34 & 34 \\
\hline & Fuel Inlet Temperature & & & & &
\end{tabular}

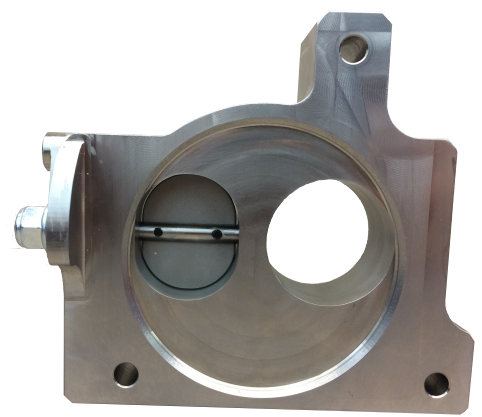

Figure 3: Engine swirl valve

2 bar BMEP.

\subsection{Temperature distribution map}

To analyze the spatial distribution of local temperatures and its variation, bi-dimensional temperature fields were calculated. Temperature distributions were obtained through linear interpolation and extrapolation from a limited number of measurement locations. In Figure 4, two temperature maps showing the temperature field in the cylinder liner and on a section of the cylinder head are presented. Measurement locations are marked with a black dot and the real temperature measured at that point is shown. Operating conditions are those corresponding to engine speed $1500 \mathrm{rpm}$ and 8 bar BMEP with a swirl number of 1.38 (minimum).

In Figure 4 (a) temperature distribution on a section of the cylinder head located at $4 \mathrm{~mm}$ above combustion chamber can be seen. In this study, valve temperatures are unknown; that is why the distribution 
Table 4: Test plan.

\begin{tabular}{lcccc}
\hline Engine speed (rpm) & 2000 & 2000 & 1500 & 1500 \\
\hline Nominal BMEP (bar) & 2 & 5 & 8 & 14 \\
\hline Nominal load (\%) & 10 & 25 & 50 & 80 \\
\hline \multirow{2}{*}{ Swirl number (at IVC) } & $1.38,2.00$, & $1.38,2.13$, & $1.38,2.00$, & $1.38,2.00$, \\
& $2.48,2.95$ & $2.48,2.95$ & $2.48,2.95$ & $2.48,2.95$ \\
\hline
\end{tabular}

does not take into account any heating of the area around valve seats.

In Figure 4 (b) the complete liner is represented. Horizontal axis is the angle of the complete cylinder circumference, starting from the center of the exhaust side that coincides with the thrust side on the piston. Vertical axis is height from firedeck $(0 \mathrm{~mm})$ to end of stroke (axis bottom). The resulting graph shows a complete cylinder liner "unrolled" over a plane. Data in Figure 4 (b) is not from the same cylinder as data in Figure 4 (a). That is because the cylinder with a higher number of thermocouples in the liner was different from the one that had more thermocouples in the cylinder head.

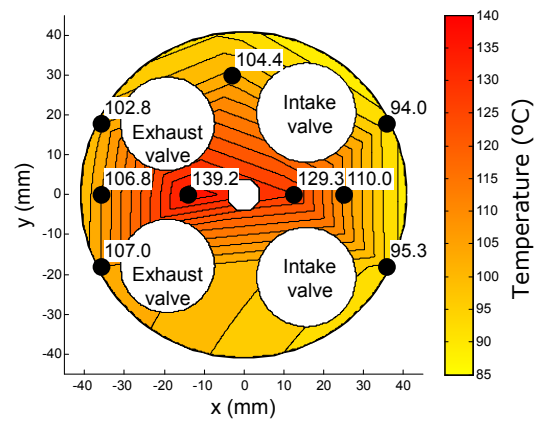

(a) Firedeck (4 mm from surface)

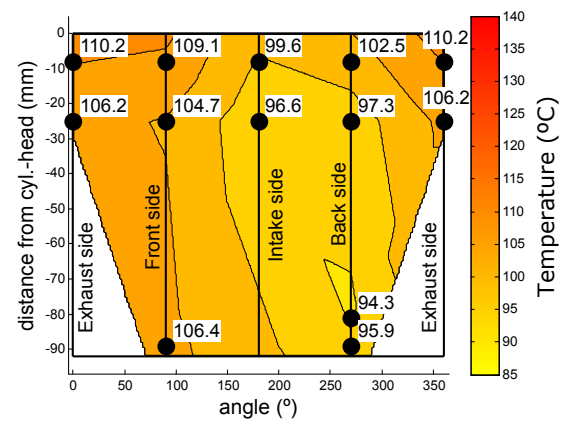

(b) Liner (1.3 $\mathrm{mm}$ from surface)

Figure 4: 1500@8 Temperature distributions

\subsection{Temperature spatial averaging}

A mean temperature of the entire firedeck section was calculated from discrete measurements. An area surrounding every thermocouple was assigned to it. Area division is displayed in Figure 5 (a). Thermocouple locations are marked with circles. Temperatures measured by each thermocouple were averaged according to the respective weight of its area in relation to the total section area (see equation 4). Valves were not included in the procedure.

$$
\bar{T}_{\text {firedeck }}=\frac{\sum_{i} T_{i} A_{i}}{\sum_{i} A_{i}}
$$

To calculate temperatures of areas 5 and 6, a different methodology was used. First, two temperatures were calculated using the averaging procedure: a mean temperature of the exhaust quarter formed by areas 
1, 2, 3 and 4 and an average temperature of the intake quarter formed by areas 7, 8, 9, and 10. Then a factor was used to calculate temperature of areas 5 and 6 , employing equation 5 .

$$
T_{5,6}=T_{\text {intake_quarter }} \alpha+T_{\text {exhaust_quarter }}(1-\alpha)
$$

where $\alpha$ is an averaging factor. The criterion to choose its value was that the resulting temperature was close to temperature measured by the only thermocouple in area 5 .

An analogous procedure was used to obtain a mean temperature of the whole cylinder liner. In Figure 5 (b), the four circles represent temperatures measured by thermocouples. Horizontal axis is distance along the cylinder liner from firedeck to the end of the piston stroke. For the length between firedeck and the first thermocouple, located at $8 \mathrm{~mm}$ below cylinder head, temperature $T_{1}$ was assumed constant and equal to the one measured by that thermocouple. Between thermocouple located $89 \mathrm{~mm}$ below cylinder head and the end of the stroke, temperature $T_{5}$ measured by the last thermocouple was assumed. For the other portions, temperature was the mean of measurements at both ends. Resulting temperatures are marked with a thick line and numbered. Then, temperature was averaged according to distance as in equation 6 . Since four vertical lines of thermocouples separated $90^{\circ}$ were present in each cylinder, equation 7 was used to obtain mean cylinder temperature as the mean of four average temperatures.

$$
\begin{gathered}
\bar{T}_{\text {side } 1}=\frac{T_{1}(8-0)+T_{2}(25-8)+T_{3}(81-25)+T_{4}(89-81)+T_{5}\left(L_{\text {total }}-89\right)}{L_{\text {total }}} \\
\bar{T}_{\text {liner }}=\frac{\bar{T}_{\text {side } 1}+\bar{T}_{\text {side } 2}+\bar{T}_{\text {side } 3}+\bar{T}_{\text {side } 4}}{4}
\end{gathered}
$$

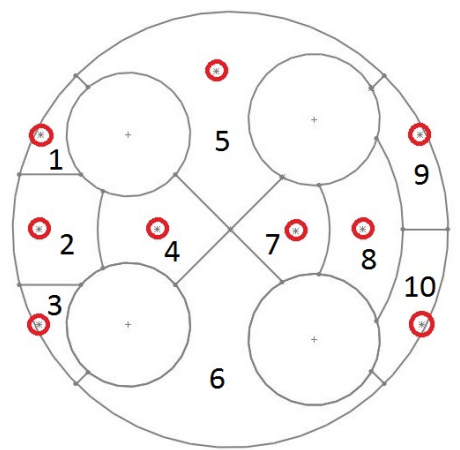

(a) Cylinder Head

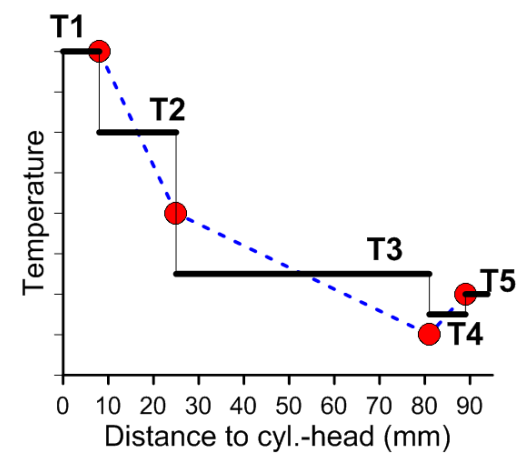

(b) Cylinder Liner

Figure 5: Averaging procedure

\section{Experimental measurements: effect of swirl on wall tem- peratures}

\subsection{Cylinder head}

\subsubsection{Single location measurements}

Measurements from a single thermocouple are shown in Figure 6 (a). Thermocouple location is marked as a circle in Figure 7. That thermocouple has been chosen because measured trends are representative and can 
be seen clearly. Operating point 2000@5 was selected because variation of swirl induced noticeable changes in wall temperature. Temperature variation with swirl number is plotted. Temperature variation with swirl number starts with an increase from SN 1.38 to SN 2.13, then there is a reduction from SN 2.13 to SN 2.48 , and finally temperature rises again from $\mathrm{SN} 2.48$ to $\mathrm{SN} 2.95$. Overall increment was around $6{ }^{\circ} \mathrm{C}$. Temperature increase can be explained by the increase in heat transfer coefficient and by the enhancement of in-cylinder mixing. If the mixing process is accelerated, more energy from fuel is released near TDC when thermal and fluid-dynamic conditions as well as area-to-volume ratio favor heat transfer. Figure 6 (b), shows the shape of the Rate of Heat Release (RoHR). In the tests ranging from SN 1.38 to SN 2.13 both slope and peak of the RoHR curve increase. A steeper slope for the RoHR indicates increased mixing and faster combustion whike a higher peak of the RoHR curve implies more heat transfer. It must be noted that fuel consumption was kept constant for all the swirl parametric study, so the total amount of energy released did not change. Regarding the tests ranging SN from 2.13 to 2.95, slopes are similar but peaks vary. The highest peak and also the highest wall temperature occur at test with SN 2.95. Peak of test SN 2.13 is higher than peak of test SN 2.48. This result can explain the wall temperature drop from SN 2.13 to SN 2.48. Mixing and burning velocity were similar for those levels of swirl numbers, but when peak is higher there is more heat transfer and therefore wall temperature is higher. A complementary explanation is supported by CFD studies published by Wiedenhoefer and Reitz [19] and some of the luminosity measurements obtained by Miles [12]. According to them, when swirl velocity increases, stronger centrifugal forces move lower temperature, higher density gases outward. Higher temperature gases stay in the middle of the combustion chamber and away from walls. Therefore, boundary layer temperature is lower and less heat is transferred to walls. Besides, in [19], an upward movement of hot gases was observed for even higher swirl numbers that contributes to explain the later temperature increase.

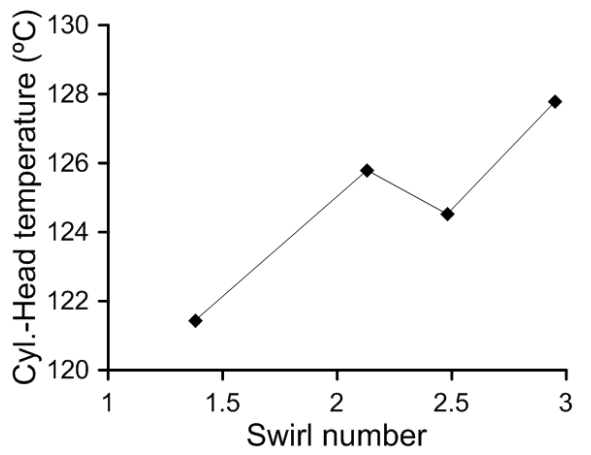

(a) Temperature VS swirl number

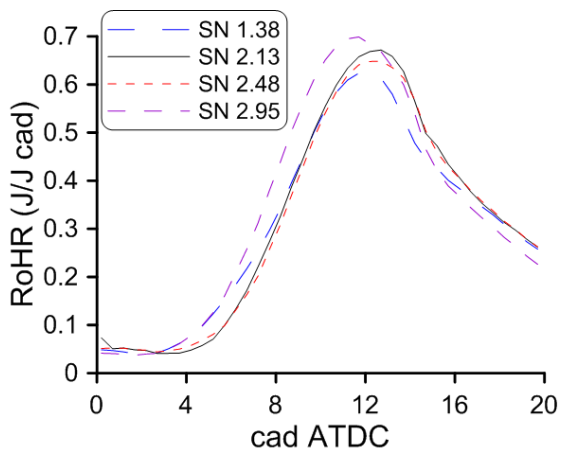

(b) Rate of Heat Release

Figure 6: 2000@5 Temperatures at one single location of cylinder head

An extension of the study can be made for all operating conditions. In Figure 8 (a), temperature measurements of one single thermocouple and all operating points are plotted versus swirl number. Measurements shown correspond to the thermocouple marked in Figure 7. To better compare the effects, temperature variations given by equation 8 have been plotted in Figure 8 (b).

$$
\Delta T_{i}=T_{i}(\mathrm{SN})-T_{i}\left(\mathrm{SN}_{\min }\right)
$$

where $i$ is the operating point: $\mathrm{i}=2000 @ 2,2000 @ 5,1500 @ 8,1500 @ 14$. It can be observed that temperature variations of operating points $2000 @ 5$ and $1500 @ 8$ were very similar in trend and magnitude. It seems that the effect of increasing load from 2000@5 to 1500@8 (from 25 to $50 \%$ ) was compensated by decreasing engine speed (and so decreasing swirl velocity to keep the same swirl number). However, trends of operating points 


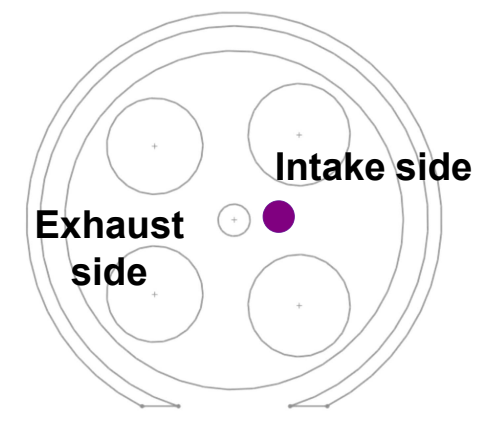

Figure 7: Section of firedeck $4 \mathrm{~mm}$ above combustion chamber

2000@2 and 1500@14 were more linear. Phenomena that cause a temperature drop for intermediate swirl numbers may not be present in those latter operating points or they may take place with swirl ratios out of the considered range. Besides, smaller temperature variation of $2000 @ 2$ must be a result of its low load $(10 \%)$. Temperature variations of 1500@14 were quite similar in magnitude to 2000@5 and 1500@8 despite the fact that load was considerably higher $(80 \%)$. It can be concluded that, at some point, an increase in load does not enhance the swirl effect anymore.

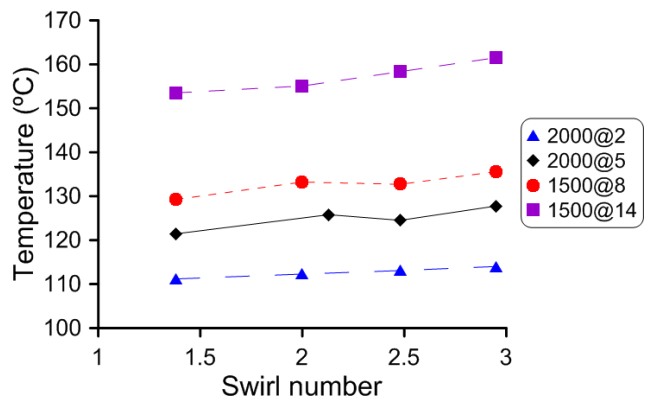

(a) Temperatures

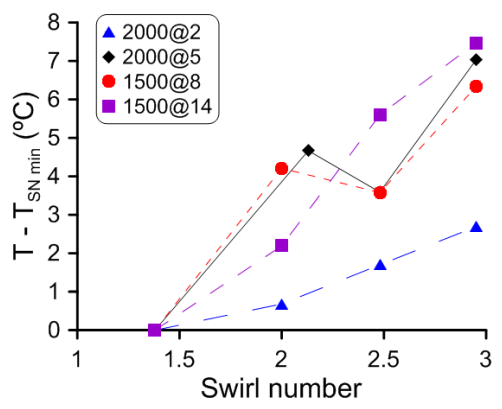

(b) Temperature variations

Figure 8: Influence of swirl in cylinder head for different operating points

\subsubsection{Distribution map and local variations}

Local effects of swirl were assessed by comparing individual thermocouples and by making a distribution map of a section of the firedeck. Figure 9 shows the map with the spatial distribution of temperature variations due to swirl. In other words, equation 8 was applied to all thermocouples of the cylinder head, using $T_{i}(\mathrm{SN})=T_{i}\left(\mathrm{SN}_{\max }\right)$ and $\mathrm{i}=1500 @ 8$. Then, the interpolation procedure explained in section 4.2 was employed. Operating point 1500@8 was selected because, as seen in Figure 8, swirl induced considerable temperature variations.

In Figure 10 (a), temperature variations are compared at some locations over the range of swirl ratios tested. Locations are marked in Figure 10 (b) with their corresponding symbols. Thermocouples located near the cylinder center measured higher variations. First, coolant channels are further from the central area, so metal temperatures are more sensitive to changes in in-cylinder conditions than in outer areas closer 


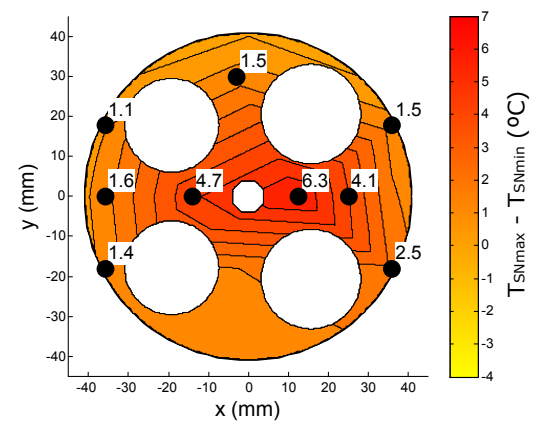

Figure 9: 1500@8 Map of temperature increments between lowest and highest swirl ratio in firedeck ( $4 \mathrm{~mm}$ above surface)

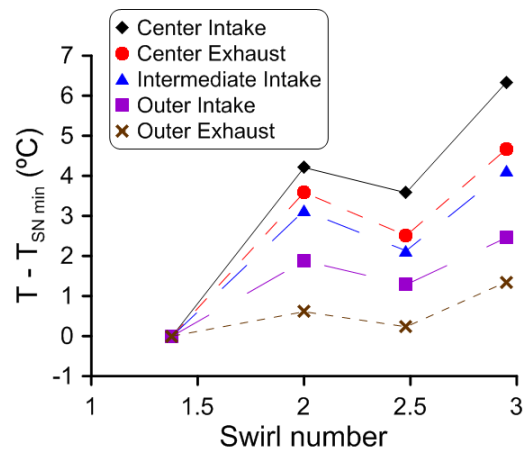

(a) Temperature variation at different locations

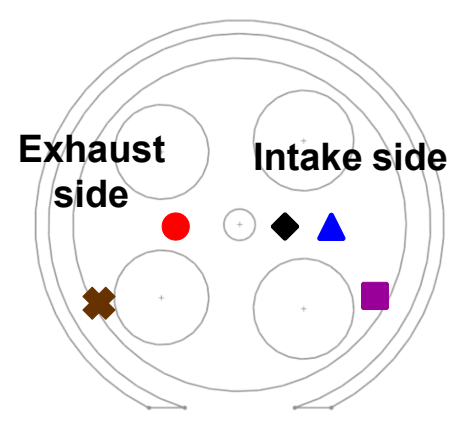

(b) Section of firedeck $4 \mathrm{~mm}$ above combustion chamber

Figure 10: 1500@8 Influence of swirl on local temperatures of cylinder head

to coolant streams. In addition, injection induced turbulence is higher in the cylinder center and increases heat transfer coefficient. Moreover, a phenomenon of confinement of hot gases near to the cylinder axis due to buoyancy has been described previously [19]. It is also noticeable that, close to the center, on the intake side temperature increases more than on the exhaust side. That can be due to different causes. On the one hand, in Figure 4 (a) it can be seen that temperature of the point on the exhaust side was higher than on the intake side. As temperature difference between it and the chamber gas was higher, there was more heat transfer. On the other hand, coolant galleries on the exhaust side are bigger, so intake side is more sensitive to in-cylinder conditions. Lastly, as swirl movement was generated in the intake ports, it is possible that the area around them was more affected by it [36].

\subsection{Cylinder liner}

\subsubsection{Single location measurements}

Measurements at the cylinder top are expected to be more sensitive to changes in operating conditions than those on the rest of the cylinder. Movement of the piston causes the area near TDC to have a longer 
exposure time to hot gases. Hence, a thermocouple at the top of the cylinder was chosen to show the evolution of wall temperatures when swirl number was swept. The selected thermocouple was located in a cooled region of the cylinder liner, $8 \mathrm{~mm}$ below cylinder head, as shown in Figure 11. For this study it must be noted that all liner thermocouples were located $1.3 \mathrm{~mm}$ from the cylinder surface.

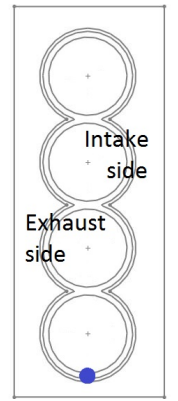

(a) Top view

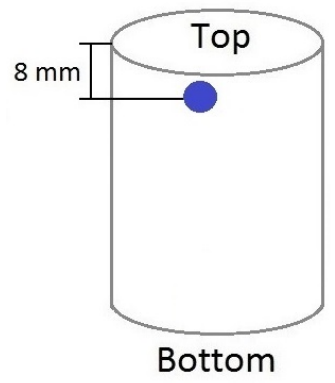

(b) Side view

Figure 11: Location of the thermocouple in the cylinder liner

Figure 12 (a) shows temperature evolution with swirl number. Measurements of the same thermocouple for all operating points have been plotted. To assess differences among operating points, impact of swirl was compared in Figure 12 (b). At operating point with higher load 1500@14, the highest temperature variation was registered. With regard to 1500@8 (load 50\%), increments were slightly larger than those of operating points 2000@5 and 2000@2, with lower loads but higher engine speeds. It can be observed that 2000@5 and 1500@8 have the same characteristic trend - drop for intermediate swirl numbers, then the rise - seen before in the cylinder head. Temperature variations were smaller than those shown in Figure 8 (b), that correspond to a thermocouple located near the center of the firedeck. In general, it can be said that the trends at the top of the cylinder liner were similar to those observed in the outer region of cylinder head -see Figure 10 (a).

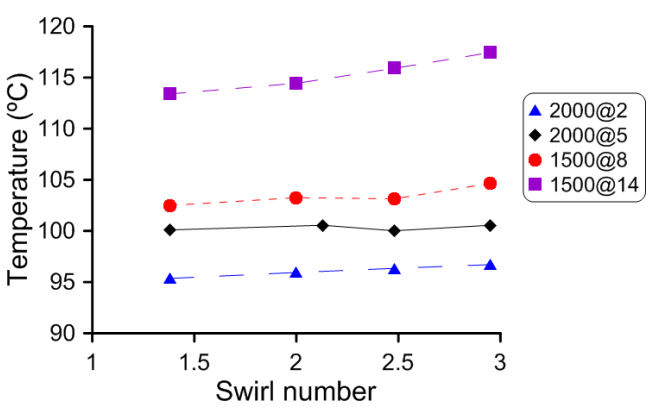

(a) Temperatures

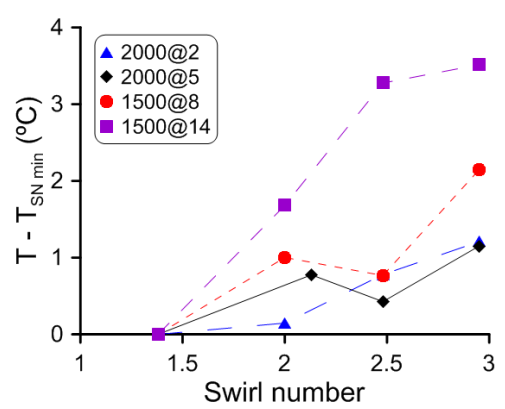

(b) Temperature variations

Figure 12: Influence of swirl in cylinder liner for different operating points 


\subsubsection{Distribution map}

Operating point 2000@5 was selected to study local trends in liner temperatures. Values were obtained with equation 8 for $\mathrm{SN}=\mathrm{SN}_{\max }$ and i (operating point) = 2000@5. Since temperature differences in Figure 13 are very small, it is difficult to observe clear trends related to location. Only two statements can be made: temperature variations are generally larger on the cylinder top and swirl produces a temperature increase there.

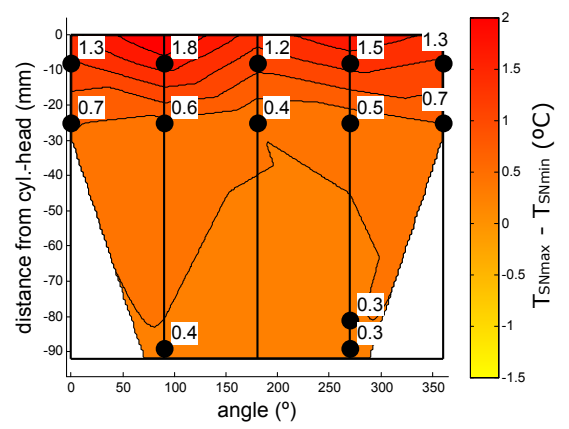

Figure 13: 2000@5 Map of temperature increase in cylinder liner for a swirl increase from SN 1.38 to $\mathrm{SN} 2.95$

\section{Comparison between model temperatures and experimen- tal measurements}

Previously discussed measurements were compared to temperatures calculated with a thermal model explained in section 2.1.1. The comparison will allow evaluating the ability of the model to simulate the influence of swirl on engine temperatures. In addition, the model was validated in another engine and so the overall capacity to predict temperatures in the engine under current study will be tested too.

First, mean temperature values in cylinder head and in cylinder liner were studied. Modeled temperatures are averaged according to the area exposed to gas of each node. The averaging procedure of experimental measurements as explained in section 4.3 was replicated for the thermal model. Temperatures of cylinder head correspond to a section $4 \mathrm{~mm}$ above the firedeck. For this part, operating point $2000 @ 2$ was selected. In Figure 15 (a) results are presented. For this particular operating point, both magnitudes and trends of mean temperatures were well predicted. However, slope of modeled temperatures was slightly larger than slope of measured temperatures. Thus, the model overestimates swirl effect slightly.

Next, a check was done to ensure that trends of local temperatures were not different from those of mean temperatures. Measurements of one particular thermocouple in the cylinder head were compared to temperatures of the node that is situated at an identical location in the model. Location is shown in Figure 14. The same has been done for one thermocouple in the cylinder liner. Its location is the same as that of the thermocouple used in section 5.2.1 - $8 \mathrm{~mm}$ below the firedeck, $1.3 \mathrm{~mm}$ deep from the chamber surface, in a cooled area of the liner. The comparison between experiment and model can be seen in Figure 15 (b). The model is able to predict the temperature in the liner with good accuracy. At the chosen location of cylinder head, temperature was slightly underestimated, but the error was between 1 and $2{ }^{\circ} \mathrm{C}$. Again, a very slight overestimation of trend can be detected. Therefore, local behaviors agree with global trends.

Finally, different operating points were compared in order to observe how error evolves when load and engine speed change. Figure 16 shows the difference between modeled and measured mean temperatures 


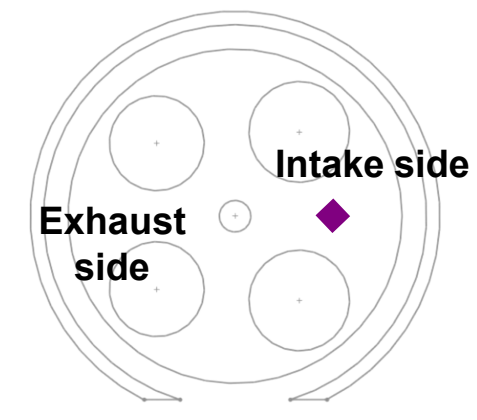

Figure 14: Section of firedeck $4 \mathrm{~mm}$ above combustion chamber

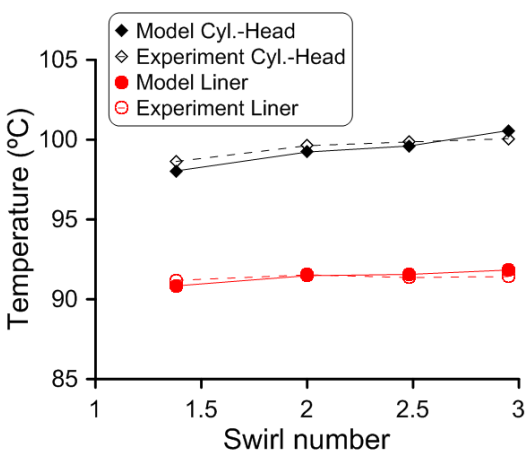

(a) Mean temperatures

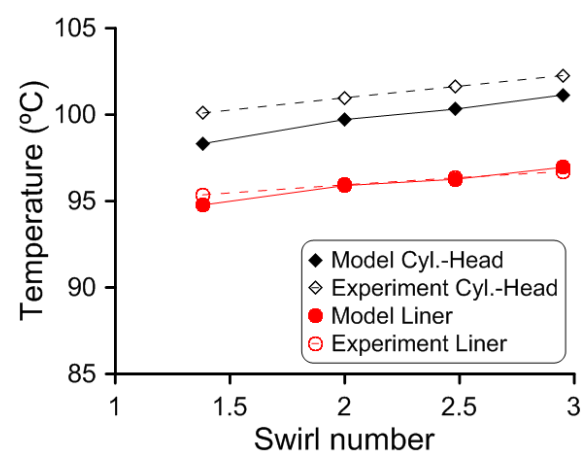

(b) Local temperatures

Figure 15: 2000@2 Comparison between measured and modeled temperatures

for all operating points. In Figure 16 (a), cylinder head mean temperatures are compared. Operating points $2000 @ 2$ and $1500 @ 8$ have errors close to zero. Temperatures for the $2000 @ 5$ operating point are overestimated between 2 and $4{ }^{\circ} \mathrm{C}$ and temperatures for the $1500 @ 14$ operating point are underestimated around $6^{\circ} \mathrm{C}$. Thus, the impact of engine speed on wall temperatures seems to be slightly amplified with respect to measurements, while engine load had smaller influence than in measurements. Profiles of 2000 rpm points have positive slopes, meaning that trends are systematically overestimated. On the right side, results for the cylinder liner indicate that temperature was predicted with an error smaller than $3{ }^{\circ} \mathrm{C}$, while trends were very similar to those seen in cylinder head.

In Figure 17, local predictions are analyzed for all operating points. Locations are the same as in Figure 15. In cylinder head (Fig 17 a), temperatures were slightly underestimated (up to $6{ }^{\circ} \mathrm{C}$ ) for higher load points 1500@8 and 1500@14, while trends agree well. Cylinder liner errors are plotted in Figure 17 (b). An overestimation of swirl effect - positive, monotonically increasing slope - can be seen at higher engine speed points $2000 @ 2$ and $2000 @ 5$. At the 2000@5 operating point, temperature was overestimated up to $6{ }^{\circ} \mathrm{C}$.

In general, agreement between model and experiment was very good. Errors of modeled mean temperatures were smaller than $5 \%$ with respect to experimental temperatures for all operating points. Trends were slightly overestimated at some operating conditions, while in other cases they agreed quite well. In conclusion, the 0-D thermal model was able to emulate the influence of swirl number variation and the magnitude of predicted temperatures was close to measurements. 


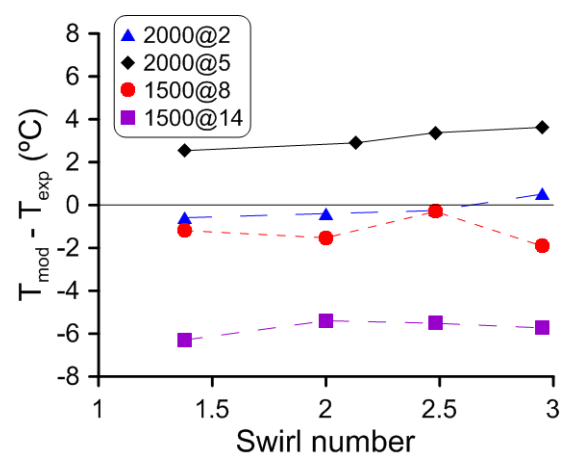

(a) Cylinder head

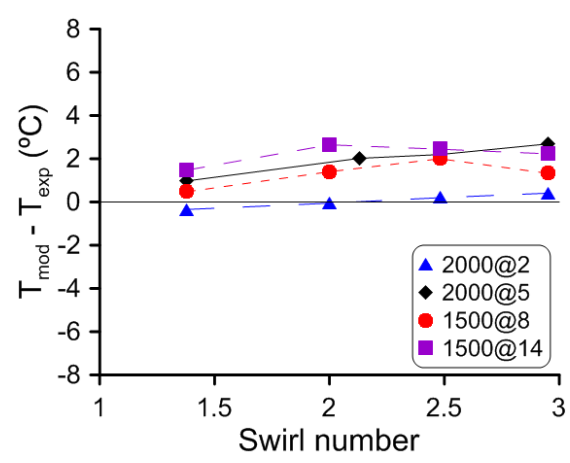

(b) Cylinder liner

Figure 16: Errors in mean temperatures for different operating points

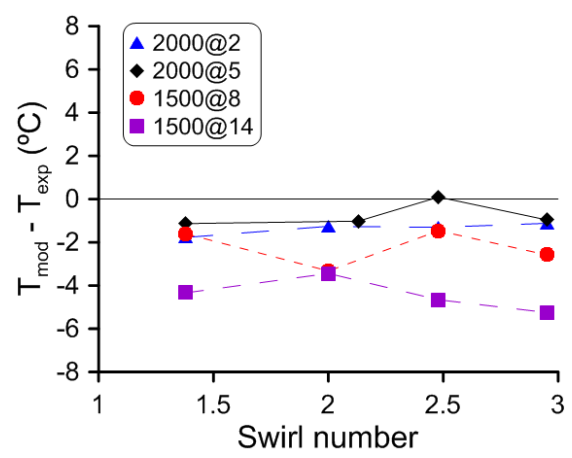

(a) Cylinder head

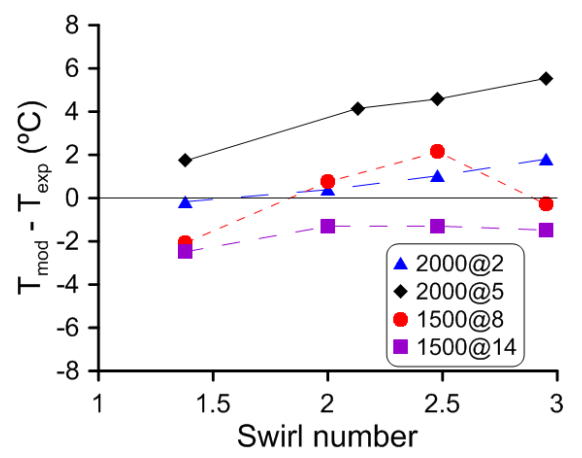

(b) Cylinder liner

Figure 17: Errors in local temperatures for different operating points

\section{Impact of swirl on heat fluxes}

\subsection{Heat fluxes through firedeck}

\subsubsection{Experimental axial temperature gradients}

In the cylinder head, all thermocouples were situated on two planes at two different distances from combustion chamber. For every thermocouple present at height $4 \mathrm{~mm}$ there was a thermocouple at height $7 \mathrm{~mm}$ with the same position coordinates - except for height over firedeck. Thus, it was possible to calculate the axial temperature gradient between each pair of sensors. If uniform conductivity is assumed, that gradient is proportional to the axial component of heat flux, as follows from equation 10. Moreover, if a conductivity value is chosen considering that the cylinder head is made of an aluminum alloy, axial heat fluxes can be calculated from those temperature gradients.

$$
\nabla T=\frac{T(4 m m)-T(7 m m)}{7 m m-4 m m}
$$




$$
Q_{\text {axial }}=\frac{k A}{d} \Delta T \rightarrow q_{\text {axial }}=\frac{Q_{\text {axial }}}{A}=k \nabla T
$$

where $Q_{\text {axial }}$ is the axial component of heat flux, $\mathrm{k}$ is thermal conductivity, A is contact area and $\mathrm{d}$ is distance.

The influence of swirl on the axial component of heat flux was analyzed. First, a map of the cylinder head with the temperature gradient field is provided in Figure 18. Operating point is 1500@8 with minimum swirl number $(\mathrm{SN}=1.38)$. It can be observed that gradient distribution is similar to temperature distribution seen in Figure 4 (a). That is explained because the further from combustion chamber, the more spatially uniform wall temperatures are. On the one hand, heat source is further and, on the other hand, coolant at almost constant temperature is closer. Thus, spatial gradient distribution must be similar to temperature distribution of the plane closer to the combustion chamber. Another issue is that heat flux was expected to be higher on the exhaust side than on the intake side because the former receives more cooling flow due to configuration of the cooling channels. In addition, where temperature was higher, the influence of gas temperature must have been stronger. In consequence, axial temperature differences and so vertical heat flux were higher where sensitivity to in-cylinder conditions was larger. For that reason, those areas are also expected to be more affected by changes in parameters such as swirl number.

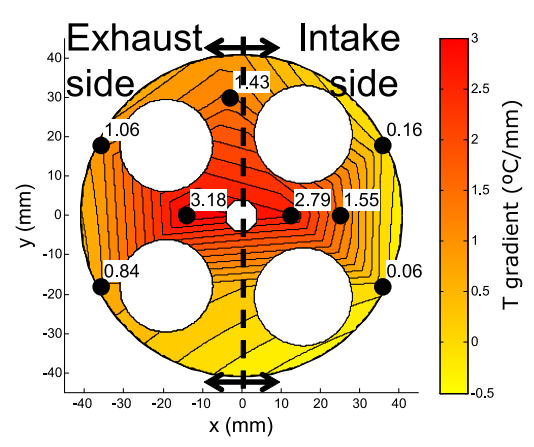

Figure 18: 1500@8 Axial temperature gradient distribution in cylinder head

Figure 19 shows that trends of axial gradients were, in general, very similar to those of wall temperatures -see Figure 8. Selected thermocouple was the same used in previous analysis and marked in Figure 7. Since it was justified above that trends of temperature gradients must be similar to those observed in wall temperatures, the explanation of phenomena such as the gradient drop for intermediate swirl ratios in operating points 2000@5 and 1500@8 is the same that can be found in section 5.1.

Local influence of swirl was assessed at operating point 1500@8. Axial gradient variations with swirl are plotted in Figure 20. Each plotted value was the gradient at that location with SN 2.95 less the gradient at that location with $\mathrm{SN}$ 1.38. It is clear that gradient increase is higher close to the cylinder center, as previously reasoned. Regarding the two thermocouples closer to cylinder center, for the two points of engine speed $2000 \mathrm{rpm}$ and lower load, gradient on the intake side increased more than gradient on the exhaust side, while for the points at $1500 \mathrm{rpm}$ and higher load, the opposite happened. Proximity of cooling galleries becomes a more important factor as global wall temperatures rise due to higher engine load.

\subsubsection{Axial heat fluxes}

Heat flux was calculated from experimental temperature gradients as in equation 10, assuming a conductivity value of $144 \mathrm{~W} / \mathrm{m} \mathrm{K}$ [6]. At the same time, predicted heat flux was obtained with the thermal model. To check if the model was able to replicate experimental trends locally, heat flux per unit area was 


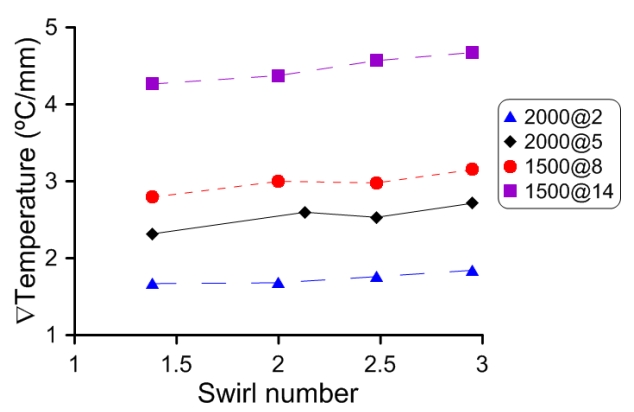

(a) Temperature gradients

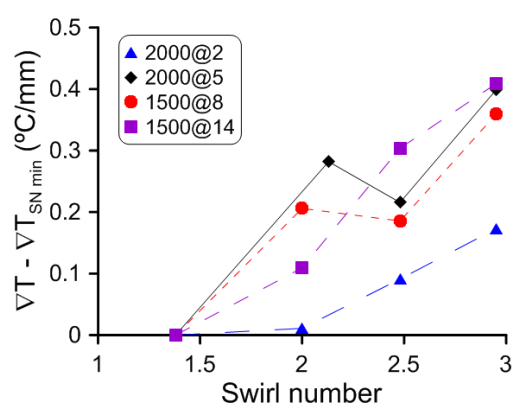

(b) Temperature gradient variations

Figure 19: Influence of swirl on axial temperature gradients for different operating points

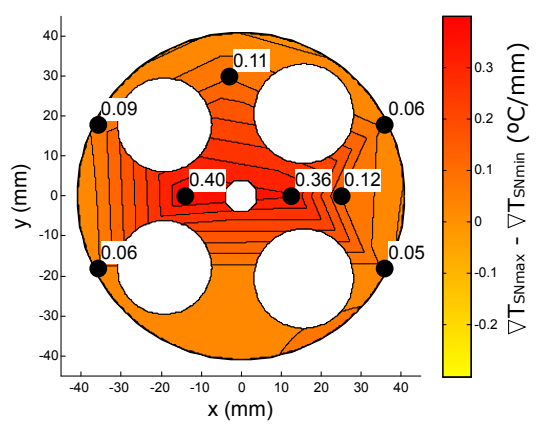

Figure 20: 1500@8 Axial gradient variations in cylinder head due to swirl

used. Direction for the heat flux is along the cylinder axis. Other spatial components such as the radial component are not included. In Figure 21 (a), model predictions are compared to experimental data at two locations of cylinder head. Locations are marked in Figure 21 (b) with their symbols and numbers. Operating point is 1500@14. It is a high load point so influence of swirl on temperatures further from the center is noticeable. There was very good agreement between model and experiment both for trends and for magnitude of the heat flux. The effect of swirl was to increase heat flux with a constant slope between SN 1.38 and SN 2.48, while from SN 2.48 to SN 2.95 slope was still positive but smaller.

Next, mean heat flux in the whole area was calculated. Results obtained correspond to heat flux in a solid, cylindrical-shaped volume located between two circular sections, one at $4 \mathrm{~mm}$ above the combustion chamber and the other one at $7 \mathrm{~mm}$ above chamber. A circular area has been used for equation 10. Diameter is equal to cylinder bore. Areas of valves have been subtracted from the total area. Besides, heat flux corresponds to one cylinder, not the sum of the four engine cylinders.

Trends of experimental heat fluxes in Figure 22 (a) are very similar to those of temperatures. Relative magnitudes among operating points are also similar to Figure 8 (a). In operating points $2000 @ 2$ and 1500@14, swirl increases the heat flux monotonically. In 2000@5 and 1500@8, heat losses decrease from the second value of swirl number to SN 2.48, as happens with temperatures. Regarding the modeled trends of those two operating points, average trends were good but the mentioned drop in heat flux does not appear or was limited to a reduction in slope. Trend of operating point 1500@14 was very similar to the experimental one. For 2000@2, swirl effect was somewhat overestimated because slope of modeled heat 


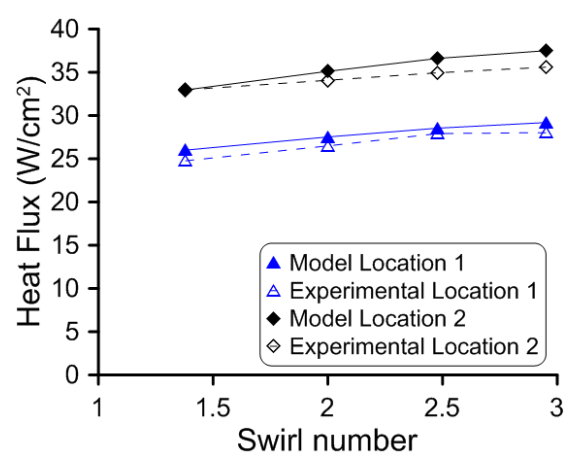

(a) Local axial gradients

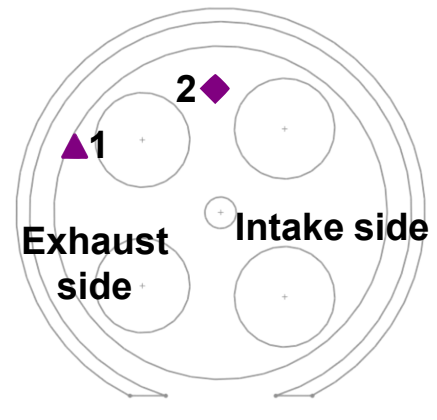

(b) Section of firedeck $4 \mathrm{~mm}$ above combustion chamber

Figure 21: 1500@14 Modeled and measured gradients in cylinder head

losses was higher than in the experimental flux. Agreement of heat flux values seems to be proper. Model tends to underestimate heat losses but the error was smaller than $10 \%$. It must be taken into account that the calculated value of experimental heat flux presented some uncertainties since the mean heat flux was obtained through an averaging procedure from discrete data points. It was not possible to know the exact temperature distribution in the firedeck. Small divergences in the averaging result have a large effect on the mean heat flux value. For instance, for the values of $1500 @ 14$, a systematic difference of $1 \%$ in all temperatures $T_{i, 4 \mathrm{~mm}}$-see equation 11, where i was a particular location- changes $\overline{\Delta T}$ and the mean heat flux by 17 to $19 \%$.

Figure 22 (b) shows impact of swirl on axial heat flux. Plotted quantities are the percentage variations in heat losses with respect to the heat flux value at SN 1.38. The biggest impact was at operating point $2000 @ 5$, with an increase in heat transfer up to $20 \%$. The rest of operating points present similar values of up to $12 \%$ of additional losses. Trends of the mentioned variations were similar to those seen in temperatures, gradients and heat fluxes. In Table 5, values representing the average heat lost through firedeck in axial direction are shown for every unit that swirl number is increased. It can be seen how significant the impact of swirl on heat losses is at each operating condition.

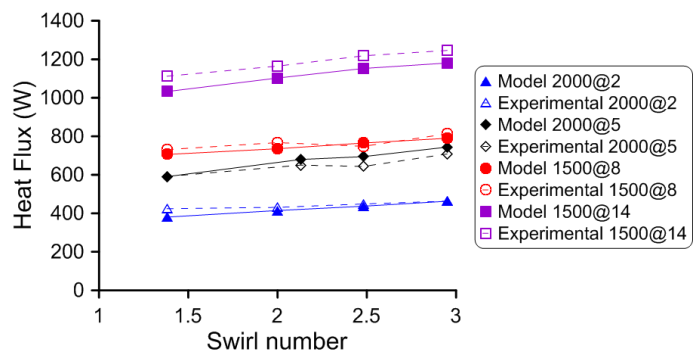

(a) Mean heat flux

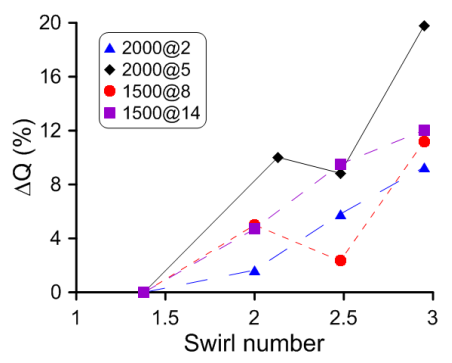

(b) Variation of mean heat flux

Figure 22: Mean heat flux through firedeck in axial direction 


$$
Q_{\text {mean }}=A \frac{\sum_{i} q_{i} A_{i}}{\sum_{i} A_{i}}=\frac{k A}{d} \frac{\sum_{i}\left(T_{i, 4 m m}-T_{i, 7 m m}\right) A_{i}}{\sum_{i} A_{i}}=\frac{k A}{d} \frac{\sum_{i} \Delta T_{i} A_{i}}{\sum_{i} A_{i}}=\frac{k A}{d} \overline{\Delta T}
$$

Table 5: Average increase in heat losses due to swirl.

\begin{tabular}{cc}
\hline Operating point & Axial heat flux increment (\%/SN) \\
\hline $2000 @ 2$ & 4.62 \\
$2000 @ 5$ & 11.34 \\
$1500 @ 8$ & 5.77 \\
$1500 @ 14$ & 7.97 \\
\hline
\end{tabular}

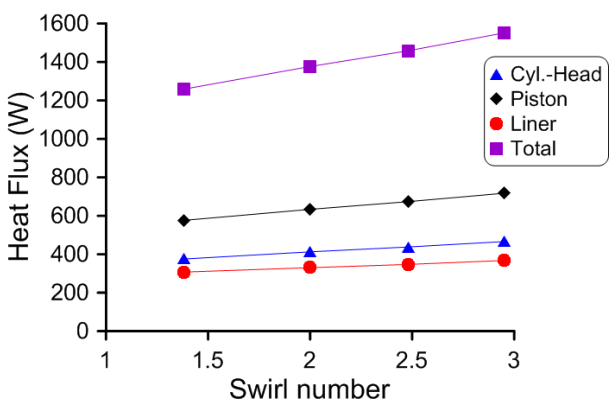

(a) $2000 @ 2$

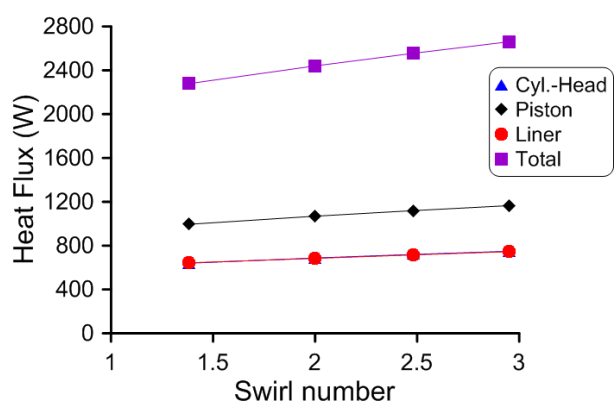

(c) $1500 @ 8$

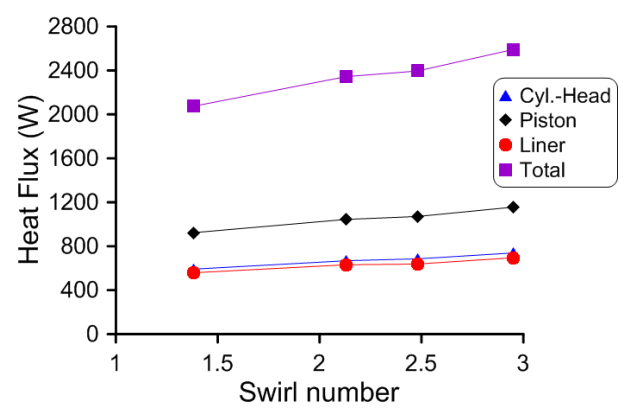

(b) $2000 @ 5$

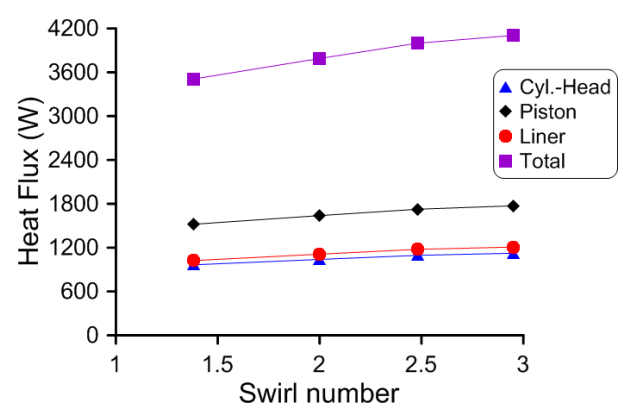

(d) $1500 @ 14$

Figure 23: Mean heat fluxes in the combustion chamber for different operating conditions

\subsection{Global heat flux in the engine}

Finally the global heat losses from combustion chamber to walls were calculated. Heat flux from chamber gas to cylinder head, cylinder liner and piston were obtained with the thermal model. They were used to understand how heat transfer was modified by swirl and by the engine operating conditions. Four graphs, 
one for every operating point, are presented in Figure 23. First interpretation is that, according to model, swirl increases heat losses globally. Heat flux is higher in piston, liner and cylinder head. Trends can vary slightly depending on the operating point. Piston receives more heat than liner or firedeck. Swirl has an evident impact on heat loss through the piston due to the intense swirl motion inside the bowl and the effects of swirl on combustion.

\section{Conclusions}

Influence of swirl on heat transfer was assessed by experimental and theoretical means. Wall temperatures were measured by means of an installation of 54 thermocouples in cylinder head and 34 thermocouples in cylinder liner. Measurements in some unprecedented locations were made and detailed information about wall temperatures close to combustion chamber was obtained. Various operating points and swirl ratios were tested. Thermocouples arrangement in firedeck allowed calculating heat flux from wall temperatures. Local and global trends were analyzed. Results of a 0-D thermal model were compared with experimental measurements and it was then used to calculate the remaining heat fluxes in the combustion chamber.

- The highest impact of swirl was found in the center of firedeck. Effects in the outer area of cylinder head and on the top of cylinder liner were smaller and similar. Regarding the rest of cylinder liner, influence of swirl was generally negligible. In addition, it was found that trends of wall temperatures, temperature gradients and heat flux were very similar if boundary temperatures - coolant, oil, intake air, ambient - were maintained constant.

- In relation to mean heat flux, experimental data show that the percentage of additional heat lost through the firedeck for increasing a unit of swirl number is around 4 to $12 \%$, depending on the operating conditions.

- The 0-D thermal model was able to simulate temperatures and heat fluxes properly. Influence of swirl ratio was slightly overestimated. According to the model, high swirl ratios increased heat losses in chamber globally, as was expected.

In conclusion, heat losses can be reduced significantly by using low swirl combustion systems.

\section{Acknowledgments}

The authors acknowledge General Motors Global R\&D for supporting this research. The equipment used in this work was partially supported by FEDER project funds "Dotación de infraestructuras científico técnicas para el Centro Integral de Mejora Energética y Medioambiental de Sistemas de Transporte (CiMeT), (FEDER-ICTS-2012-06)", framed in the operational program of unique scientific and technical infrastructure of the Ministry of Science and Innovation of Spain.

\section{References}

\section{References}

[1] W. Knecht, Diesel engine development in view of reduced emission standards, Energy 33 (2) (2008) 264-271. doi:10.1016/j.energy.2007.10.003.

[2] J. B. Heywood, Internal Combustion Engine Fundamentals.

[3] A. J. Torregrosa, P. Olmeda, J. Martín, B. Degraeuwe, Experiments on the influence of inlet charge and coolant temperature on performance and emissions of a DI Diesel engine, Experimental Thermal and Fluid Science 30 (7) (2006) 633-641. doi:10.1016/j.expthermflusci.2006.01.002. 
[4] A. Broatch, J. M. Luján, S. Ruiz, P. Olmeda, Measurement of hydrocarbon and carbon monoxide emissions during the starting of automotive DI Diesel engines, International Journal of Automotive Technology 9 (2) (2008) 129-140. doi:10.1007/s12239-008-0017-6.

[5] S. Soid, Z. Zainal, Spray and combustion characterization for internal combustion engines using optical measuring techniques. A review, Energy 36 (2) (2011) 724-741. doi:10.1016/j.energy.2010.11.022.

[6] F. P. Incropera, D. P. DeWitt, T. L. Bergman, A. S. Lavine, Fundamentals of Heat and Mass Transfer, Vol. 6th of Dekker Mechanical Engineering, John Wiley \& Sons, 2007.

[7] A. C. Alkidas, Effects of Operational Parameters on Structural Temperatures and Coolant Heat Rejection of a S.I. Engine, SAE Paper.

[8] I. C. Finlay, G. R. Gallacher, T. W. Biddulph, R. A. Marshall, The Application of Precision Cooling to the Cylinder-Head of a Small, Automotive, Petrol Engine, in: SAE Paper, 1988. doi:10.4271/880263.

[9] G. Borman, K. Nishiwaki, Internal-combustion engine heat transfer (1987). doi:10.1016/03601285(87)90005-0.

[10] C. Finol Parra, Heat transfer investigations in a modern diesel engine, Ph.D. thesis (2008).

[11] J. H. Van Gerpen, C.-W. Huang, G. L. Borman, The Effects of Swirl and Injection Parameters on Diesel Combustion and Heat Transfer, in: SAE, 1985. doi:10.4271/850265.

[12] P. C. Miles, The Influence of Swirl on HSDI Diesel Combustion at Moderate Speed and Load, in: SAE, 2000. doi:10.4271/2000-01-1829.

[13] S. Kook, C. Bae, P. Miles, D. Choi, M. Bergin, R. Reitz, The Effect of Swirl Ratio and Fuel Injection Parameters on CO Emission and Fuel Conversion Efficiency for High-Dilution, Low-Temperature Combustion in an Automotive Diesel Engine, SAE Paper 2006 (2006-01-0197). doi:10.4271/2006-01-0197.

[14] J. de la Morena, A. Vassallo, R. C. Peterson, V. Gopalakrishan, J. Gao, Influence of Swirl Ratio on Combustion System Performance of a 0.4L Single-Cylinder Diesel Engine, in: THIESEL, 2014, pp. $1-19$.

[15] W. G., Die Berechnung der Wandverluste und der thermischen Belastung der Bauteile von Dieselmotoren, MTZ 31 Nr 12 (1970) 491-499.

[16] C. A. Finol, K. Robinson, Thermal modelling of modern engines: A review of empirical correlations to estimate the in-cylinder heat transfer coefficient, Proceedings of the Institution of Mechanical Engineers, Part D: Journal of Automobile Engineering 220 (2006) 1765-1782. doi:10.1243/09544070JAUTO202.

[17] G. F. Hohenberg, Advanced Approaches for Heat Transfer Calculations, in: SAE Paper, Vol. 790825, 1979. doi:10.4271/790825.

[18] C. Arcoumanis, P. Cutter, D. S. Whitelaw, Heat Transfer Processes in Diesel Engines, Chemical Engineering Research and Design 76 (2) (1998) 124-132. doi:10.1205/026387698524695.

[19] J. F. Wiedenhoefer, R. D. Reitz, Multidimensional Modeling of the Effects of Radiation and Soot Deposition in Heavy-duty Diesel Engines, SAE Paper.doi:10.4271/2003-01-0560.

[20] F. Payri, J. Luján, J. Martín, A. Abbad, Digital signal processing of in-cylinder pressure for combustion diagnosis of internal combustion engines, Mechanical Systems and Signal Processing 24 (6) (2010) 1767-1784. doi:10.1016/j.ymssp.2009.12.011.

[21] J. Martín, Diagnóstico de la combustión en motores diesel de inyección directa, Ph.D. thesis, Universitat Politècnica de València (2012).

[22] F. Payri, J. Galindo, J. Martín, F. J. Arnau, A Simple Model for Predicting the Trapped Mass in a DI Diesel Engine, 2007. doi:10.4271/2007-01-0494. 
[23] M. Lapuerta, O. Armas, J. Hernández, Diagnosis of DI Diesel combustion from in-cylinder pressure signal by estimation of mean thermodynamic properties of the gas, Applied Thermal Engineering 19 (5) (1999) 513-529. doi:10.1016/S1359-4311(98)00075-1.

[24] F. Payri, P. Olmeda, J. Martín, A. García, A complete 0D thermodynamic predictive model for direct injection diesel engines, Applied Energy 88 (12) (2011) 4632-4641. doi:10.1016/j.apenergy.2011.06.005.

[25] F. Payri, S. Molina, J. Martín, O. Armas, Influence of measurement errors and estimated parameters on combustion diagnosis, Applied Thermal Engineering 26 (2-3) (2006) 226-236. doi:10.1016/j.applthermaleng.2005.05.006.

[26] F. Payri, X. Margot, A. Gil, J. Martín, Computational Study of Heat Transfer to the Walls of a DI Diesel Engine, SAE Technical Papers (2005-01-0210). doi:10.4271/2005-01-0210.

[27] J. Benajes, P. Olmeda, J. Martín, R. Carreño, A new methodology for uncertainties characterization in combustion diagnosis and thermodynamic modelling, Applied Thermal Engineering 71 (1) (2014) 389-399. doi:10.1016/j.applthermaleng.2014.07.010.

[28] A. J. Torregrosa, P. Olmeda, J. Martín, C. Romero, A Tool for Predicting the Thermal Performance of a Diesel Engine, Heat Transfer Engineering 32 (10) (2011) 891-904.

[29] S. V. Bohac, D. M. Baker, D. N. Assanis, A Global Model for Steady State and Transient S.I. Engine Heat Transfer Studies, in: SAE, 1996. doi:10.4271/960073.

[30] J. R. Wagner, E. E. Marotta, I. Paradis, Thermal Modeling of Engine Components for Temperature Prediction and Fluid Flow Regulation, Tech. rep. (2001). doi:10.4271/2001-01-1014.

[31] A. Torregrosa, P. Olmeda, B. Degraeuwe, M. Reyes, A concise wall temperature model for di Diesel engines, Applied Thermal Engineering 26 (11-12) (2006) 1320-1327.

[32] A. Torregrosa, A. Broatch, P. Olmeda, J. Martín, A contribution to film coefficient estimation in piston cooling galleries, Experimental Thermal and Fluid Science 34 (2) (2010) 142-151. doi:10.1016/j.expthermflusci.2009.10.003.

[33] P. Olmeda, V. Dolz, F. Arnau, M. Reyes-Belmonte, Determination of heat flows inside turbochargers by means of a one dimensional lumped model, Mathematical and Computer Modelling 57 (7-8) (2013) 1847-1852. doi:10.1016/j.mcm.2011.11.078.

[34] Drivven Inc., DRIVVEN stand alone direct injector driver system user's manual.

[35] F. Payri, P. Olmeda, J. Martin, R. Carreño, A New Tool to Perform Global Energy Balances in DI Diesel Engines, SAE International Journal of Engines 7 (1) (2014) 43-59. doi:10.4271/2014-01-0665.

[36] C. D. Rakopoulos, G. C. Mavropoulos, Experimental evaluation of local instantaneous heat transfer characteristics in the combustion chamber of air-cooled direct injection diesel engine, Energy 33 (7) (2008) 1084-1099. doi:10.1016/j.energy.2008.02.003. 